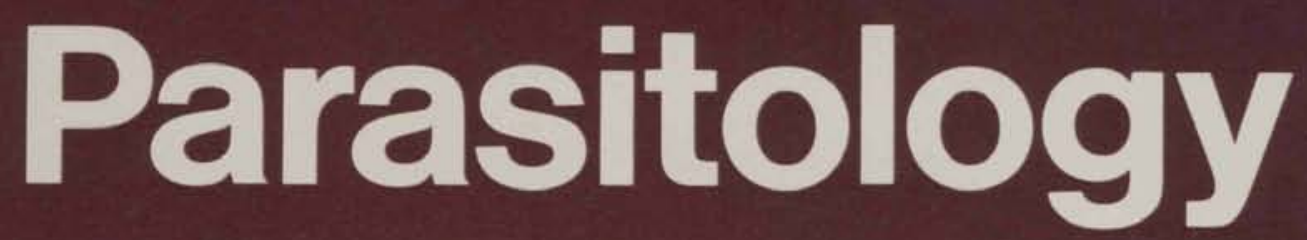

Symposia of the British Society for Parasitology Volume 28 Parasite neurobiology

EDITED BY D W HALTON

CO-ORDINATING EDITOR L. H. CHAPPELL 
Subscriptions may be sent to any bookseller or subscription agent or direct to the publisher: Cambridge University Press, The Edinburgh Building, Shaftesbury Road, Cambridge CB2 2RU. Subscriptions in the USA and Canada should be sent to Cambridge University Press, Journals Department, 40 West 20th Street, New York, NY 10011-4211. All orders must be accompanied by payment. The subscription price of volumes 102 and 103 , 1991 is $£ 156$ UK, £,161 elsewhere (US $\$ 336$ in the USA and Canada), payable in advance, for six parts and any supplements; separate parts cost $£ 24$ or US $\$ 50$ each (plus postage). Second class postage paid at New York, NY and at additional mailing offices. POSTMASTER: send address changes in USA and Canada to Parasitology, Cambridge University Press, 110 Midland Avenue, Port Chester, New York, NY 10573-9864. 


\title{
Parasitology
}

Symposia of the British Society for Parasitology Volume 28

\section{Parasite neurobiology}

\author{
EDITED BY \\ D. W. HALTON
}

CO-ORDINATING EDITOR

L. H. CHAPPELL

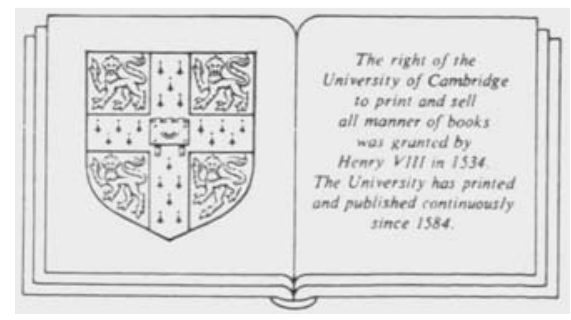

CAMBRIDGE UNIVERSITY PRESS CAMB R I DGE

NEW YORK PORT CHESTER MELBOURNE SYDNEY 


\section{Contents}

Preface

List of contributions

Acknowledgements

Chairman's opening remarks

\section{Evolutionary aspects of transmitter molecules, their receptors and channels}

Introduction

Classification of transmitter molecules

Properties of a synapse

Voltage-gated channels and ligand-gated ion channels

Ligand-gated channels

Evolution of ion channels

Overview of the physiological roles for transmitters

Neuroactive peptides and co-localization

Transmitters in platyhelminths

Transmitters in nematodes

Transmitters in arthropods

Summary

References

\section{Neurobiology of parasitic} platyhelminths: possible solutions to the problems of correlating structure with function

Summary

Introduction

Neuroanatomical localization of putative neurotransmitters

Physiological action of small molecule neurotransmitters

Pharmacology, biochemistry and role of second messengers in the action of small molecule neurotransmitters

Neuropharmacology

Biochemistry

Second messengers

Studies on isolated helminth muscle cells Patch clamping

Quantitative fluorescence cytometry

Discussion

References

\section{The physiology and pharmacology of neuromuscular transmission in the nematode parasite, Ascaris suum}

Summary

Introduction

Locomotory behaviour
Nervous system

Basic structure of Ascaris nervous system

Non-spiking motoneurones of Ascaris

Physiological interconnections of motoneurones

Muscle

$\mathrm{S} 42$

Anatomy

$\mathrm{S} 43$

$\mathrm{S} 43$

Morphology of somatic muscle cells

$\mathrm{S} 43$

Electrophysiology

$\mathrm{S} 45$

Electrical activity of muscle cells

Ascaris muscle has acetylcholine and GABA receptors

Ionic basis of the electrical responses to acetylcholine and GABA

Biochemistry

Biochemistry of acetylcholine

Pharmacology

$\mathrm{S} 46$

$\mathrm{S} 46$

$\mathrm{S} 47$

Pharmacology of the acetylcholine receptor

Pharmacology of the GABA receptor

$\mathrm{S} 48$

Arylaminopyridazine derivatives $\quad$ S49

Biophysics

S54
Muscle vesicle preparation

ACh single-channel currents

GABA single-channel currents

Ivermectin

Effects of dihydroavermectin

Other transmitters

The action of 5-HT

Other possible neurotransmitters

Second messengers

Conclusion

References

\section{Neurobiology of arthropod parasites}

Introduction

Acetylcholine

Neurotransmitter at excitatory synapses in the CNS of acarine parasites

Mechanism of resistance to organophosphates in ticks

$\gamma$-Aminobutyric acid

Neurotransmitter at inhibitory synapses in the CNS and muscle of ticks

Action of avermectins in the muscle and CNS of ticks

S51

S51

S52

$\mathrm{S} 53$

S53

$\mathrm{S} 53$

$\mathrm{S} 53$

S54

$\mathrm{S} 54$

S54

S55

S59

Glutamate

S61

Neurotransmitter at excitatory neuromuscular junctions in the muscle of ticks

Biogenic amines

Noradrenaline as a neurotransmitter in ticks 
Octopamine as a neuromodulator in acarine parasites

Dopamine as a neurotransmitter at excitatory synapses in the salivary glands of ticks

Neuropeptides

Occurrence and function in ticks

Concluding remarks and future opportunities

References

Introduction to neuropeptides : perspectives for the parasitologist

Introduction

Neuropeptide biosynthesis

Selecting a peptidergic system

Release and action of peptides

Peptide inactivaton

Conclusion

\section{Neuropeptides in platyhelminths}

Historical perspective

Significance of the neurosecretory (peptidergic) system in platyhelminths

Demonstration of neurosecretory elements in platyhelminths

S65

S65

S65

S66

S71

S71

S71

S73

S74

S75

S75

S77

S77

S78

ocalization and distribution of peptides in parasitic platyhelminths

Isolation of 'native' parasite peptides

Physiological roles of peptides in platyhelminths

Conclusions

Future directions

References

Role of regulatory peptides in parasitic platyhelminths and their vertebrate hosts: possible novel factors in host-parasite interactions

Introduction

Why study regulatory peptides in parasitic platyhelminths?

Why study regulatory peptides in their vertebrate hosts?

S87

$\mathrm{S} 88$

S93
Methods of regulatory peptide characterization

Characterization of pancreatic polypeptide immunoreactivity in Schistosoma mansoni and its laboratory host, the mouse

Characterization of pancreatic polypeptide immunoreactivity in Diclidophora merlangi and its teleostean fish host, the whiting (Merlangius merlangus)

Characterization of tachykinin immunoreactivity in Diclidophora merlang $i$ and the whiting (Merlangius merlangus)

Characterization of regulatory peptide immunoreactivities in Haplometra cylindracea and the lung tissue of its frog host, Rana temporaria

Characterization of vasoactive intestinal peptide (VIP) and peptide histidine isoleucine (PHI) immunoreactivity in the tapeworm, Moniezia expansa, and the intestine of its host, the sheep

Conclusion

References

Neuropeptides in the nematode Ascaris suum

Introduction

Immunocytochemical study of neuropeptide diversity

Variety of peptide-like immunoreactivities

Chemical characterization and physiological activity of endogenous Ascaris peptides

Discussion

S108

Peptide families

$\mathrm{S} 110$

$\mathrm{S} 112$

$\mathrm{S} 112$

Differential localization

$\mathrm{S} 113$

Other methods for searching for novel peptides

Relationship to other nematodes

S114

References

S114

Chairman's concluding remarks 